\title{
APROXIMAÇÕES EXPLORATÓRIAS ENTRE ANTONIO GRAMSCI E O ESPORTE'
}

\author{
GRAD. FABRÍCIO LUÍS DUARTE² \\ Graduado em Ciências Sociais pela Faculdade de Artes, Filosofia e Ciências Sociais da Universidade \\ Federal de Uberlândia (FAFCS-UFU) (Uberlândia - Minas Gerais - Brasil) \\ E-mail: fabricioduartesocio@gmail.com
}

\section{RESUMO}

Por diversas hipóteses, as quais vêm sendo levantadas em estudos recentes, o interesse de Antonio Gramsci pelo esporte foi próximo de zero. Entretanto, suas lucubrações e seu legado são profícuos, pois contribuem indiretamente à intelecção desse fenômeno, um dos mais expressivos da atualidade. Este trabalho tem como objetivo trazer à tona um pouco dessa discussão, isto é, aproximar de forma exploratória Antonio Gramsci e o esporte. Para tanto, foi realizada uma revisão bibliográfica, que buscou investigar a obra do filósofo sardo, alguns de seus intérpretes no Brasil, bem como artigos de estudiosos do esporte que utilizam Gramsci como referencial teórico-metodológico, fundamentalmente da literatura anglófona.

PALAVRAS-CHAVE: Esporte; Antonio Gramsci; hegemonia; estudos culturais.

\section{GRAMSCI E O ESPORTE: DIÁLOGOS PERTINENTES ${ }^{3}$}

Antonio Gramsci, nascido no ano de 1891, em Ales, província de Cagliari, na Ilha de Sardenha, uma das regiões italianas mais pobres e atrasadas, e um dos fundadores do Partido Comunista da Itália ( 192 I), teve uma vida marcada por privações. De saúde frágil, ele, aos quatro anos, caiu dos braços de uma babá, fato muitas vezes relacionado ao seu problema físico, qual seja, ter se tornado corcunda. Entretanto, estudos recentes atribuem essa debilidade à doença de Pott, uma tuberculose vertebral diagnosticada no cárcere, mas contraída na infância, quando Gramsci tinha 18 meses.

Sentenciado pelo regime fascista de Mussolini a 20 anos, 4 meses e 5 dias de reclusão, Gramsci padeceu de males atrozes durante anos no cárcere. No Tribunal

I. Esta pesquisa contou com aportes da FAPEMIG (modalidade bolsa de iniciação científica).

2. Um agradecimento ao professor e orientador de monografia Edilson José Graciolli pelos comentários.

3. Este artigo brotou da intenção tanto de aprofundar algumas das discussões introdutórias sobre Gramsci e o esporte feitas por Valter Bracht, as quais estão presentes em seu livro intitulado Sociologia crítica do esporte: uma introdução, como de trazer novos problemas ao debate e fomentar as pesquisas. 
Especial, em que ele e o grupo dirigente do PCl foram julgados, o promotor Michele Isgrò asseverou: "Devemos impedir esse cérebro de funcionar durante vinte anos". Em virtude de sua saúde debilitada, Gramsci foi libertado: isso funcionou como uma manobra de Mussolini para evitar que ele morresse como prisioneiro do fascismo. Pouco tempo depois da sua libertação, aos 46 anos, em 27 de abril de 1937, ele faleceu.

Diante desse definhamento, não é inconcebível o desinteresse de Gramsci pelo esporte. $\bigcirc$ fato de o esporte não ter retido sua atenção também pode, por hipótese, estar ligado às concepções dominantes que tiveram vigência nas últimas décadas. Por muitos anos, e os resquícios perduram até hoje, o esporte foi encarado, mesmo por alguns intelectuais, como um fato cotidiano trivial, carente de maiores significados, desprovido de qualquer relevância às ciências humanas e sociais. ${ }^{4}$

Apesar da negligência de outrora, mudanças vêm ocorrendo nesse panorama, visto que o interesse pela compreensão do esporte cresce a cada dia no mundo contemporâneo. Como qualquer outro fenômeno social, o esporte, que, ainda assim, permanece como um dos menos estudados do nosso tempo, deve ser tratado e estudado rigorosa e seriamente, pois, talvez como nenhum outro, goza de ampla credibilidade, reunindo quase unanimidade quanto à sua legitimidade social, e, presente em todo o mundo, é sem dúvida, um dos mais expressivos da atualidade.

Como é sabido, Gramsci colaborou intensamente com a imprensa socialista, sendo um de seus principais articuladores na Itália. Sua atividade jornalística teve início em dezembro de 1915, quando ele começou a trabalhar na redação do jornal Avanti!. É justamente em tal periódico, que se encontra um pequeno artigo dele sobre o esporte, o qual foi publicado sem assinatura, em 1918, na coluna "Sotto la Mole", e intitulado O futebol e o baralho. Nesse breve escrito de sua "juventude intelectual", publicado nos Escritos Políticos, Gramsci afirmou: "O esporte é atividade difundida nas sociedades onde o individualismo econômico do regime capitalista transformou os costumes e, ao lado da liberdade econômica e política, suscitou também a liberdade espiritual e a tolerância em face da oposição" (GRAMSCl, 2004, p. 210).

A despeito de sua sensibilidade para com inúmeros aspectos da vida da classe trabalhadora italiana, Gramsci não deu atenção às primeiras edições da Copa do

4. No campo do marxismo, o trabalho do historiador Eric Hobsbawm apresenta contribuições interessantes ao entendimento do esporte. Para dar apenas um exemplo, em História social do jazz, Hobsbawm explicita que existem "trabalhadores ingleses que vão a jogos de futebol debaixo da chuva ou neve, em vez de assisti-los melhor e mais confortavelmente pela TV, pois a participação direta, a vibração da torcida que faz o time jogar melhor, é tão importante para o entretenimento quanto a mera visão dos jogadores" (HOBSBAWM, 1990, p. 37). 
Mundo de Futebol organizadas pela FIFA (Federação Internacional das Associações de Futebol), competição que era muito popular tanto entre os socialistas e comunistas, como entre os fascistas (BAIRNER, 2009). Nas duas edições seguintes à primeira Copa, de 1930, sediada e vencida pelos uruguaios, o time italiano, conhecido como Squadra Azurra, sagrou-se bi-campeão: em 1934, na própria Itália, e em 1938, na França, pouco mais de um ano após a morte de Gramsci, ambas realizadas à época do regime fascista de Mussolini.

Devido à grande repercussão da primeira Copa do Mundo no Uruguai, o governo fascista italiano empenhou-se intensamente em concretizar a nova edição do Mundial:

Sempre atento a qualquer potencialidade em torno da mobilização nacional, o Estado fascista percebeu claramente toda a dimensão que o futebol poderia alcançar em uma estrutura de poder que valorizava o culto da força e do combate. Ficava claro que, mais do que qualquer expressão esportiva, caracterizava um sem número de metáforas belicistas, o que se aplicava perfeitamente aos valores fascistas (AGOSTINO, 2002, p. 57).

Com vistas à Copa de 1934, foi construído um estádio na cidade de Turim, de enorme magnitude, com potencial para acomodar setenta mil pessoas, que recebeu o nome de Benito Mussolini, uma homenagem ao ditador italiano. A obra de Gramsci, cujo espírito obtém inúmeras vitórias póstumas, inspira o conhecimento dessa vasta estrutura ideológica capaz de influir na "opinião pública" (entre aspas a fim de realçar que a mesma é socialmente construída), que comporta não somente a imprensa, mas também "as bibliotecas, as escolas, os círculos e os clubes de variados tipos, a arquitetura, a disposição e o nome das ruas" (GRAMSCl, 2006b, p. 78).

De diversas formas e por vezes, o governo fascista italiano auferiu proveito do futebol e dos Mundiais. Isso não se restringiu à primeira edição vencida pelo time italiano, na qual o Duce (que significa líder, no idioma italiano), como era chamado Mussolini, foi ovacionado entusiasticamente, aclamado na final da competição aos gritos de "DU-CE, DU-CE, DU-CE" (AGOSTINO, 2002, p. 62). Por ocasião da conquista do segundo campeonato mundial em Paris, Mussolini exaltou a "força e a excelência atlética, além do valor espiritual da juventude fascista, no coração da capital de um país, onde as idéias, a propaganda e os métodos empregados, todos são antifascistas" (MURAD, 2007, p. I I 5).

Todavia, não se deve confundir, como frequentemente ocorre, esse uso político como "pura" manipulação política, alijando, assim, do processo de dominação, sua dimensão relacional. Muitas vezes, as estratégias e ações dominantes geram reações não planejadas, inesperadas, efeitos nem sempre favoráveis. $\mathrm{Na}$ Copa de 1938, em virtude de uma declaração de Mussolini, em que ele hostilizava 
o governo francês, ocorreram protestos já na primeira partida da Squadra Azurra, realizada contra a Noruega: "as manifestações contra os jogadores italianos fizeram o estádio tremer" (AGOSTINO, 2002, p. 64). O time italiano representava uma nação que "sucumbiu" aos desígnios fascistas, donde a relevância desses protestos. Com isso, o presente trabalho busca, entre outras coisas, corroborar a ideia de que a relação esporte/espectador (além da relação mais atual existente entre esporte e telespectador, caracterizada pela mediação da TV e da Internet), não é de absoluta dominação, simplesmente passiva, pois o real é eivado de contradições.

Sendo assim, não obstante o interesse quase nulo ao qual foi feito menção, a obra de Gramsci representa um legado inestimável para os estudos socioculturais do esporte. Seus escritos, fundamentalmente os que concernem à sua "maturidade intelectual", os Cadernos do cárcere, ${ }^{5}$ redigidos entre 1929 e 1935, passaram a exercer forte influência nas pesquisas sobre o esporte, mormente em países anglófonos, como Estado Unidos, Canadá, Inglaterra e Austrália, pois a eficácia analítica das categorias engendradas por Gramsci transcende em muito seu tempo e país.

Por certo, a problemática fundamental que subjaz aos Cadernos, à qual Gramsci busca dar resposta, é a seguinte: por que a revolução socialista não aconteceu precisamente onde o capitalismo era mais avançado? Por que, apesar da aparente situação revolucionária, de crise econômica aguda, não foi possível repetir a experiência da Revolução de Outubro, efetuada pelos bolcheviques na Rússia (1917), em parte da Europa Ocidental? Para Gramsci, tal insucesso deve ser imputado ao fato de não ter sido levado em devida conta uma diferença estrutural, de natureza histórico-social, e não puramente geográfica, a saber, a existente entre as formações sociais "orientais", abalizadas pela debilidade da "sociedade civil", bem como pela predominância quase absoluta do "Estado-coerção", como no caso da Rússia czarista, e as formações sociais "ocidentais", em que a "sociedade civil" é bem desenvolvida, nas quais o poder da classe dominante repousa principalmente no consenso, e não mais na primazia do "Estado" (stricto sensu) e da coerção, exercida através dos aparelhos repressivos.

Nesse sentido, o processo de "ocidentalização" concerne ao desenvolvimento e complexificação da "sociedade civil", referente à intrincada rede de instituições e

5. Como o próprio nome indica, os intitulados Cadernos do Cárcere referem-se a um conjunto de textos esparsos, mas ao mesmo tempo instigantes, escritos pelo filósofo sardo no período em que ele esteve preso, que só foram editados postumamente. Eles seriam posteriormente a base para escritos mais sistemáticos, o que Gramsci, por sua morte prematura, não conseguiu realizar. Não se deve desconsiderar que, apesar de aparentemente fragmentados, esses escritos conservam uma unidade teórica. Como se sabe, Gramsci jamais publicou livros em sua vida, ele apenas estampava artigos em jornais de sua época, na Itália. 
práticas, de adesão voluntária, que permeiam a vida cotidiana, as quais são responsáveis pela direção política, moral, cultural e ideológica, consagrada por Gramsci como hegemonia. ${ }^{6}$ As atividades que vigoram no âmbito da "sociedade civil" exercem "pressão coletiva" e obtêm "resultados objetivos de elaboração nos costumes, nos modos de pensar e de atuar, na moralidade, etc" (GRAMSCI, 2007, p. 23-24).

Os aparelhos "privados" de hegemonia, de adesão voluntária, e, por isso, privados, que, a seguir, estão postos à vista, são os portadores materiais da "sociedade civil":

[...] political parties, trade unions, the mass media, the family, schools, churches and all cultural processes (which would include sport, although it had far less cultural importance during the interwar period, when Gramsci was writing, than it has today) (HARGREAVES; MCDONALD, 2000, p. 49).

O esporte deve, pois, ser entendido como um aparelho "privado" de hegemonia, ${ }^{7}$ locus em que visões de mundo são elaboradas, difundidas e disputadas, essencial na luta pela hegemonia. Se o Estado é "sociedade civil + sociedade política, isto é, hegemonia couraçada de coerção" (GRAMSCI, 2007, p. 244), logo o esporte integra o "Estado em sentido ampliado" e, em tal caso, é cortado de lado a lado pela luta de classes, o que vai de encontro às interpretações recorrentes segundo as quais esse fenômeno é politicamente neutro. Para Gramsci, a luta cultural e ideológica tem um valor central no processo de reafirmação da dominação, entendida aqui não de forma mecanicista, mas dialeticamente. Ele procurou entender a autonomia e a eficácia causal das "superestruturas" culturais como um problema político. Enfim, a batalha cultural é um elemento chave na disputa por hegemonia, e o esporte ocupa uma posição estratégica nesse combate.

Toda essa discussão levada a cabo por Gramsci tem implicações na sua estratégia de transição para o socialismo. Nas sociedades "ocidentais", em função

6. Aprofundar o debate entre Gramsci e Lênin não é o objetivo deste artigo. De todo modo, cabe mencionar sumariamente que, mesmo tendo sido utilizado antes por Lênin, o conceito de hegemonia ganhou notoriedade a partir da obra de Gramsci. Além do mais, deve-se levar em conta que há uma especificidade no pensamento de Gramsci, ou seja, o conceito de hegemonia não deve ser reduzido a uma mera "aplicação" da obra de Lênin: o filósofo italiano aprofunda e enriquece a concepção leninista (DIAS, 2000).

7. Faz-se mister discriminar a prática, no caso, o esporte, da instituição, a estrutura material, como, a título de exemplo, um clube de esportes, o local da prática. Entretanto, há a possibilidade de a prática igualmente ser considerada como espaço em que acontece a elaboração, difusão e disputa de visões de mundo. Embora as fronteiras sejam bastante tênues na realidade concreta, costuma-se decompor, no plano abstrato, o esporte em esporte de alta performance, profissionalizado, ou de rendimento, e esporte amador, ligado ao "lazer", ao "tempo livre", ou "tempo de não-trabalho". 
da complexificação da "sociedade civil", ao invés de uma "guerra de movimento" (estratégia indispensável para as sociedades "orientais"), isto é, um ataque frontal voltado diretamente para a conquista e conservação do Estado (stricto sensu), é indispensável uma "guerra de posições": antes da tomada do Estado (stricto sensu), são necessárias longas batalhas a fim de conquistar posições e espaços no âmbito da "sociedade civil", na qual o esporte ocupa um lugar de destaque. Nas palavras de Gramsci:

[...] a guerra de movimento torna-se cada vez mais guerra de posição; e pode-se dizer que um Estado vence uma guerra quando a prepara de modo minucioso e técnico no tempo de paz. A estrutura maciça das democracias modernas, seja como organizações estatais, seja como conjunto de associações na vida civil, constitui para a arte política algo similar às "trincheiras" e às fortificações permanentes da frente de combate na guerra de posição: faz com que seja apenas "parcial" o elemento do movimento que antes constituía "toda" a guerra, etc. (GRAMSCl, 2007, p. 24).

A segmentação do Estado em "esferas", em "sociedade civil" somada à "sociedade política", efetuada por Gramsci, tem cunho nitidamente metodológico, visto que há superposição nas sociedades concretas. É importante, ao perscrutar a obra de Gramsci, ter em mente que a função hegemônica de classe extrapola o campo exclusivamente "superestrutural", pois as práticas ideológicas se fazem presentes desde o momento da produção econômica, no interior da fábrica. Em seu importante escrito denominado Americanismo e fordismo, ${ }^{8}$ o próprio Gramsci sublinhou que a hegemonia "nasce na fábrica" (GRAMSCI, 200 I, p. 247). A fim de fomentar a intelecção, chamo à memória uma passagem, escrita por Giulianotti, em que o conceito de hegemonia é esmiuçado:

Hegemony describes the particular fluid power relationships, methods and techniques within a class society whereby dominant groups secure their control through the ideological consent, rather than the physical coercion, of the dominated group. The exploitative social order appears 'natural', or 'common sense', ensuring that the dominated group 'lives its subordination'. Dominant groups accommodate elements of the subordinate social class within the hegemonic bloc, however resistant counter-hegemonic formations arise. Hegemony is established within differente societal domains (in politics, business and industry, cultural arenas) where various classes or class fractions enter into struggle, opposition, manipulation, compromisse, negotiation and accommodation (GIULIANOTTI, 2005, p. 49).

8. Americanismo e fordismo é fundamental a este trabalho por iluminar a intelecção sobre a atividade do corpo e o controle sobre o corpo, o que será investigado com mais rigor a seguir. 
Gramsci (2006a, p. 238) considerava um "infantilismo primitivo" a ideia segundo a qual as "superestruturas" política e ideológica são expressão imediata da "estrutura". De acordo com ele, com o testemunho de Marx, autor de obras políticas e históricas concretas, como O 18 Brumário de Luís Bonaparte, a Questão Oriental e A guerra civil na França, essa concepção deveria ser contestada. Desse modo, a obra de Gramsci vai de encontro às degenerescências economicistas, mecanicistas ou reducionistas presentes em algumas interpretações. Ele objeta tanto o economicismo como o idealismo ao afirmar que, ao contrário de um mecanicismo, existe na teoria de Marx uma "reciprocidade necessária" entre "estrutura" e "superestruturas": esse é "precisamente o processo dialético real" (GRAMSCI, 2006a, p. 25I). Em oposição ao materialismo dito "vulgar", que reduz a história a um materialismo crasso, é importante entender que as formas de consciência e as ações humanas não são meros reflexos mecânicos de um movimento "infraestrutural", simples epifenômenos da "estrutura". Nesse sentido, é importante trazer ao debate uma passagem de Marx, ${ }^{9}$ contida n'O 18 Brumário de Luís Bonaparte, fundamental para apreender a problemática da relação entre "estrutura" e "superestrutura" em sua obra:

[... o os homens fazem sua própria história, mas não a fazem como querem; não a fazem sob circunstâncias de sua escolha e sim sob aquelas com que se defrontam diretamente, legadas e transmitidas pelo passado. A tradição de todas as gerações mortas oprime como um pesadelo o cérebro dos vivos (MARX, 1974, p.7).

No campo do marxismo "ortodoxo", vertente cujas interpretações muitas vezes caracterizam-se pela simplificação exagerada dos esquemas de dominação, o esporte é compreendido meramente como um exemplo da mercantilização da vida cotidiana pelo capitalismo. Esse fenômeno é visto como um circo que distrai os trabalhadores e obstrui seu potencial revolucionário, assim como transforma os atletas em autômatos, ou seja, em robôs, e os espectadores em simples consumidores passivos.

Essas interpretações "ortodoxas", mecânicas e unilineares, incompreendem o devir histórico e a dialética do real. Tanto consumir resistindo como resistir consumindo podem ser práticas verdadeiras, o que denota uma ambiguidade. É

9. O propósito aqui não é o de analisar profundamente a relação entre Marx e Gramsci. Seguindo a indicação de Gramsci, este artigo apenas traz à discussão um trecho de $\bigcirc 18$ Brumário de Luís Bonaparte, uma obra histórico-política concreta de Marx, crucial para criticar as leituras mecanicistas e reducionistas do materialismo histórico-dialético. De todo modo, é importante mencionar que Gramsci não deixa de questionar sob alguns aspectos o pensamento de Marx. Mas isso constitui um tema amplo para outras discussões, que foge aos desígnios aqui elencados. 
semelhante ao que Chauí corrobora em seu livro intitulado Conformismo e resistência. A análise da autora sobre "cultura popular", entendida aqui não como uma cultura fechada sobre si mesma, mas dialeticamente orientada, evidencia a possibilidade real de resistir ao conformar, assim como de conformar ao resistir (CHAUÍ, 1994).

Como atividade ligada ao "tempo de não-trabalho", ao "tempo livre", o esporte está envolvido também na reprodução da força de trabalho, noção que abarca tanto a reprodução simples, física, ou orgânica, como a reprodução ampliada, referente ao reforço das qualidades pessoais necessárias ao trabalho, tais como disciplina, persistência, dedicação, ascese, pontualidade, ordem, coragem, respeito, entre outros atributos (BRACHT, 2005). Desse ponto de vista, o indivíduo é julgado a priori como ordinário suporte de determinações "infraestruturais", com pouco ou quase nenhum espaço à resistência, uma definição demasiadamente simplificada que minimaliza ou extingue a percepção da cultura como dimensão de embates e tensões, nos seus diversos matizes.

O entendimento do esporte enquanto "ópio" deriva do conceito de "falsa consciência". Para Gramsci, a ideologia não comporta esse sentido, não é negativa ou enganosa em si. Ele recusa compreender a ideologia estritamente no sentido gnosiológico, como "falsa consciência", em oposição à "consciência verdadeira" científica. A ideologia é, na verdade, uma força real, capaz de modificar a vida humana, ou seja, as visões de mundo (ou ideologias) resultam em ações práticas, racionalizam o cotidiano. À luz da obra do filósofo sardo, os indivíduos não são simplesmente enganados, ludibriados pelas ideologias dominantes; jamais as aceitam, por assim dizer, em sua forma "pura"; a combinação é sempre mais ou menos heteróclita e bizarra. Nos Cadernos há uma interessante passagem, em que Gramsci reflete sobre a religião, em especial sobre a religião católica, que permite pensar a relativa introjeção de ideologias e valores. Nela, o sardo afirma: "há um catolicismo dos camponeses, um catolicismo dos pequenos burgueses e dos operários urbanos, um catolicismo das mulheres e um catolicismo dos intelectuais, também este variado e desconexo" (GRAMSCI, 2006a, p. II5).

Essa vertente do marxismo, a qual versa sobre o esporte enquanto mecanismo para iludir o "povo", vem sendo largamente criticada pelo seu caráter determinista, estático e ahistórico. Em contraposição a tal modo de entendimento, emerge o conceito de hegemonia reelaborado por Gramsci que, tendo em vista o primado do real e, além do mais, contrapondo-se à noção pura e simples de dominação, constitui uma alternativa radical, fecunda e rigorosa aos estudos do esporte. 
Hegemony, then, is a process of experience, negotiation and struggle by individuals in real-life situations, rather than one in which subordinate groups are simply duped by dominant ideologies. In Gramsci's formulation, it is not simply a matter of class control, but an unstable process which requires the winning of consent from subordinate groups. It is, then, never 'complete' or fixed, but rather diverse and always changing (HARGREAVES; MCDONALD, 2000, p. 50).

Nessa corrente de pensamento que dá mais margem às ações humanas, abre-se espaço para a intervenção das vontades, detentoras de papel atuante na história. Ao reconhecer a importância da práxis, termo que remete às atividades humanas, compostas sempre de elementos volitivos, valorativos e teleológicos, Gramsci possibilita pensar as formas de resistência existentes no esporte, que não necessariamente têm em vista a superação da ordem do capital. Conforme foi explicitado, elas podem inclusive ser um misto de conformismo e resistência, caracterizar ambiguidade. Neste momento, trazer à discussão uma afirmação célebre de Gramsci, recheada de implicações democráticas, é fundamental. De acordo com ele, "[...] todos os homens são 'filósofos'” (GRAMSCl, 2006a, p. 93), ou seja, através de sua linguagem, de seu senso comum, todo homem, em sua ação interativa, manifesta um "conjunto de noções tanto sobre o que é como sobre o que deve ser" (COUTINHO, 2007, p. I I I, grifos do autor) o esporte. Nesse sentido, a ideologia é central na orientação prática dos homens. Toda forma de práxis, inclusive a práxis esportiva, contém a potencialidade da passagem da recepção passiva do mundo para a esfera da modificação do real. $\bigcirc$ esporte contém a política como elemento real ou potencial ineliminável, isso é um fato ontológico real.

Discorrendo sobre o papel dos intelectuais, Gramsci explicitou que "não há atividade humana da qual se possa excluir toda intervenção intelectual, não se pode separar o homo faber do homo sapiens" (GRAMSCI, 2006b, p. 52-53). Qualquer forma de atividade, por mais que seja fundamentalmente "física", ou mecânica, é uma atividade intelectual. Essa argumentação é de grande valia para o entendimento do esporte de alta performance, visto que, frequentemente, atletas-trabalhadores são considerados nulos em termos de racionalidade (a eles são direcionadas frases que remetem ao animalesco). Informado pelo pensamento de Gramsci, cabe explicitar que todos os atletas são intelectuais, todos possuem faculdades intelectuais e racionais, mas nem todos os atletas exercem uma função intelectual ordenadora, ou seja, nem todos desempenham uma atividade organizativa na sociedade.

Igualmente, as elucubrações de Gramsci constituem alternativas profícuas às concepções essencialistas da cultura, imbuídas da concepção equivocada segundo a qual, específicas práticas culturais refletem a essência de determinada classe ou fração de classe social. Perde-se de vista, nessas visões maniqueístas e dicotômicas, 
o movimento de "circularidade da cultura": práticas culturais identificadas com a classe dominante em uma definida conjuntura podem ser acopladas/ressignificadas pelas classes populares em outro momento; o movimento inverso é, do mesmo modo, percebido. Dito de outro modo, as dimensões políticas e ideológicas das formas e práticas culturais são inerentemente mutáveis, circulantes, elas são alvos de constantes disputas entre as classes e frações de classes sociais.

Em Americanismo e Fordismo, Gramsci discutiu acerca da "produção de um novo tipo de homem", o qual era exigido pela racionalização da produção e do trabalho:

[... é necessário encaminhar esta regulamentação e a criação de uma nova ética. Deve-se observar como os industriais (especialmente Ford) se interessaram pelas relações sexuais de seus empregados e, em geral, pela organização de suas famílias; a aparência de 'puritanismo' assumida por este interesse (como no caso do proibicionismo) não deve levar a avaliações erradas; a verdade é que não se pode desenvolver o novo tipo de homem exigido pela racionalização da produção e do trabalho enquanto o instinto sexual não for adequadamente regulamentado, não for também ele racionalizado (GRAMSCI, 200 I , p. 252).

Essa argumentação do filósofo sardo ecoa pelo esporte de alta performance, cada vez mais racionalizado (na busca por previsibilidade e calculabilidade), visto que um "novo tipo de esportista" (um conceito genérico) vem sendo produzido, o qual tem sua sexualidade regulamentada, configurando-se uma nova ética. Exemplar é o caso das concentrações dos times de futebol, praxe nos dias que antecedem os jogos. Trata-se, da mesma forma, entre outras coisas, de um mecanismo de controle e racionalização (podendo haver, é claro, vozes dissidentes) dos desejos sexuais dos atletas de alta performance. Conforme Gramsci (200I, p. 269), o trabalhador, e aqui é possível incluir o atleta-trabalhador, "que vai para o trabalho depois de uma noite de 'orgias' não é um bom trabalhador".

Embora a proibição do uso do álcool pelas instituições reguladoras esteja restrita neste momento a alguns esportes e competições, não é de menor importância a vigilância e o controle indireto do consumo dessa substância e da vida cotidiana dos atletas-trabalhadores empreendidos por torcedores, profissionais e aparelhos "privados" de hegemonia ligados ao esporte.

Ademais, um corpo amplo e diversificado de peritos é fundamental para engendrar esse "novo tipo de esportista": treinadores, psicólogos, nutricionistas, fisioterapeutas e médicos do esporte (abre-se um novo campo, o da medicina esportiva) são necessários, assim como o pagamento de mega-salários (mesmo restritos a uma minoria, eles servem como o ideal, são objeto da mais alta aspiração, principalmente entre os jovens, recrutados cada vez mais novos para o esporte), 
além de uma vasta propaganda ideológica, que caminha sobretudo no sentido de promover a ideologia da "ascensão social" ${ }^{0}$ via esporte (a miséria estrutural acaba transformando-se em casos individuais curáveis pela prática profissionalizada do esporte).

Chamo à memória outro comentário tecido por Gramsci, novamente em Americanismo e Fordismo, no qual ele discorre sobre a taylorização do processo de produção fabril, também crucial ao entendimento da produção desse "novo tipo de esportista":

Taylor expressa com brutal cinismo o objetivo da sociedade americana: desenvolver em seu grau máximo, no trabalhador, os comportamentos maquinais e automáticos, quebrar a velha conexão psicofísica do trabalho profissional qualificado, que exigia uma certa participação ativa da inteligência, da fantasia, da iniciativa do trabalhador, e reduzir as operações produtivas apenas ao aspecto físico maquinal (GRAMSCI, 200 I, p. 266).

Reservadas as particularidades passíveis de averiguação na análise de casos concretos, faz-se mister clarificar que o esporte sofreu um processo de taylorização. $\bigcirc$ trabalho do atleta passou a ser analisado cientificamente. Os tempos e movimentos da prática esportiva profissionalizada são cada vez mais racionalizados, com a finalidade de retirar operações desnecessárias e improdutivas do processo de trabalho, de maximizar a eficácia, o rendimento, a performance do atleta. $\bigcirc$ futebol norte-americano, um esporte moderno par excellence, cujo corpo de especialistas envolvidos em sua produção supera sobremaneira o número de jogadores, ilustra de modo exato o processo de taylorização do esporte. Esse esporte vincula atualmente esporte e "burocratização" da atividade física, resultado, em grande medida, das ações do ex-jogador e treinador Walter Camp, morto em 1925, que modelou os times da Yale University, dos Estados Unidos, conforme os modelos da estrutura taylorista de produção industrial e de gerência científica (BAIRNER, 200 I).

Além do mais, falar em hegemonia pressupõe que alguns interesses dos atletas-trabalhadores sejam atendidos; que existe, na realidade, um equilíbrio de compromisso, que eles podem negar-se a conter determinadas práticas, isto é, resistir, inclusive fazendo "corpo mole" - prática que definitivamente não se restringe ao âmbito fabril -, afinal, eles não são simplesmente manipulados, meros joguetes

10. A ideologia da "ascensão social" através do esporte não é meramente um "mito", no sentido de falsa, ilusória. Ela necessita de um ponto de tangência com a realidade para subsistir. Isso significa que alguns atletas de alta performance, a minoria, entre milhões, que se esforçam, certamente acabam obtendo êxito na profissão, servindo, por conseguinte, como exemplos de superação a serem seguidos - um tipo de propaganda intensamente apropriado e disseminado pelos aparelhos "privados" de hegemonia: rádios, TVs, jornais e revistas, entre outros. 
dos interesses dominantes. Em outras palavras, as formas de resistência são reais e persistem no fenômeno esporte.

Com propriedade, Hargreaves acrescenta à discussão, ao discorrer sobre os limites da exploração dos atletas-trabalhadores:

[... ] there seem to be limits to the exploitation of sports workers in the interests of increased productivity and profits and on the exploitation of sport for promoting respectability, or national prestige, or whatever; for the more intensive the competition, the more there is a tendency, it seems, for those involved, from administrators down to participants, to try to win by breaking the rules (drug-taking, undercover payments, violent tactics, etc.). This has obvious repercussions for the credibility as a convincing symbol of dominant values and norms, and therefore for its utility in the construction of hegemony (HARGREAVES, 1982, p. 52).

U uso de substâncias ilícitas a fim de melhorar a performance do atleta, que vende sua força de trabalho (e cuja atividade tem uma dimensão teleológica, já que ele figura na mente sua construção, a criatura, antes de transformá-la em realidade, tal como um salto), implica no descrédito do esporte perante a "opinião pública" mas, se não "descoberto" (como por vezes ocorre, e deliberadamente), "' tem por consequência o favorecimento da lógica do esporte de alta performance. Assim, é possível falar mais uma vez em ambiguidade, pois, ao buscar extrair o máximo de rendimento dos corpos, ao racionalizar o trabalho dos atletas, o doping traz benefícios à lógica do esporte profissional, vai ao encontro dos ideais competitivistas do capitalismo, confluindo com os interesses (sobretudo econômicos) das pessoas que controlam o esporte de alta performance; concomitantemente, mas no sentido contrário, caso venha à tona, o uso dessas substâncias repercute de forma negativa na "opinião pública", abrindo assim fissuras na intrincada "textura" de hegemonia, sempre em processo de recriação, já que a transgressão contraria princípios que, na "aparência" (produtora de efeitos socialmente eficazes, e não simplesmente ilusão), norteiam o esporte, tais como a competição entre os "iguais" (no caso, a ideologia da igualdade de chances), e o respeito às regras e ao próximo.

Pautado no real método marxiano, o materialismo histórico-dialético, o grande desafio a ser enfrentado nas pesquisas sobre o esporte é fazer análises concretas de situações concretas, ou seja, traduzir o concreto para o plano intelectual, opondo-se, em consequência, aos modelos de análises generalizantes, as quais lançam mão de

II. Além de demonstrar a conivência das autoridades para com o doping, Simson e Jennings (1992) deixam claro que, a despeito de existirem muitas punições de atletas por uso de substâncias proibidas, são poucos os descobertos, porque os fabricantes das drogas usadas pelos atletas estão à frente das tecnologias utilizadas para detectá-las: à medida que novos testes são introduzidos, novas substâncias para as quais não há testes são elaboradas. 
categorias genéricas, vazias de concreção, com pouco lastro, que, reificadas, terminam por reificar a própria realidade, já que são incapazes de apreender a marcha do real, a historicidade e a particularidade das categorias analíticas.

Os estudos do esporte à luz do pensamento gramsciano não passam incólumes às críticas na academia. Eles vêm suscitando inúmeras dúvidas, que estão sendo problematizadas nas pesquisas mais recentes acerca do assunto. ${ }^{12}$ De qualquer forma, não se pode negar que todos esses trabalhos, cada um à sua maneira, contribuem enormemente à intelecção do esporte, um campo de pesquisa ainda em fase de construção no Brasil, no que diz respeito às ciências humanas e sociais.

Decerto, outras questões poderiam ter sido alvo de análise neste trabalho, tal como a profissionalização do esporte, que pode ser entendida, nos termos gramscianos, enquanto "revolução passiva", uma modernização de tipo conservador. Mas, respeitando os limites de um artigo, coube apenas fazer uma breve iniciação ao fecundo legado de Gramsci no que tange aos estudos socioculturais do esporte, buscando referências em seus intérpretes no Brasil, nos seus próprios textos, assim como na literatura anglófona, isto é, em países nos quais as pesquisas acerca desse fenômeno, à luz da obra do filósofo sardo, estão em estágio mais "avançado".

Ao aproximar de forma exploratória a obra de Antonio Gramsci e o esporte, o presente artigo buscou lançar luzes à compreensão desse fenômeno, fornecendo profícuos subsídios teórico-metodológicos aos estudantes, pesquisadores, profissionais, jornalistas, enfim, a todos os envolvidos e interessados, nesse que é um dos mais significativos fenômenos da atualidade que, de uma forma ou de outra, faz parte da vida da maioria das pessoas em todo o mundo.

\section{Exploratory approximations between Antonio Gramsci and sport}

ABSTRACT: According to several hypotheses which have been raised in recent studies, Antonio Gramsci's interest in sport was close to zero. However, his lucubrations and his legacy are proficuous because they indirectly contributed to the intellection of this phenomenon which is one of the most expressive nowadays. This research has the goal of bringing to light a little of this discussion; that is, approximating Antonio Gramsci and sport in an exploratory way. For this purpose, a bibliographic review was carried out in order to investigate the work of this Sardinian philosopher, some of his interpreters in Brazil, as well as scholars of sport's articles that use Gramsci as theoric-methodological reference, mainly from Anglophone literature.

KEY WORDS: Sport; Antonio Gramsci; hegemony; cultural studies.

12. A título de exemplo, Bairner (2009) destaca que os Estudos Culturais do esporte realizados sob o prisma de Gramsci perdem a memória de sua orientação marxista e de sua história de vida, e distanciam-se, por conseguinte, de forma substancial, dos propósitos radicais de transformação social do militante revolucionário italiano. 


\section{Aproximaciones exploratorias entre Antonio Gramsci y el deporte}

RESUMEN: Por diversas hipótesis, las cuales vienen siendo levantadas en recientes estudios, el interés de Antonio Gramsci por el deporte fue próximo de cero. Sin embargo, sus elucubraciones y su legado son proficuos, puesto que contribuyen indirectamente a la intelección de ese fenómeno, uno de los más expresivos en la actualidad. Este trabajo tiene como objetivo traer a baila un poco de esa discusión, es decir, aproximar de forma exploratoria Antonio Gramsci al deporte. Para tanto, fue realizada una revisión bibliográfica que buscó investigar la obra del filósofo sardo, algunos de sus intérpretes en Brasil, así como artículos de estudiosos del deporte que utilizan a Gramsci como referencial teórico y metodológico, fundamentalmente de la literatura anglófona.

PALABRAS CLAVE: Deporte; Antonio Gramsci; hegemonía; estudios culturales.

\section{REFERÊNCIAS}

AGOSTINO, G. Vencer ou morrer: futebol, geopolítica e identidade nacional. Rio de Janeiro: FAPERJ, 2002.

ANDERSON, P. Considerações sobre o marxismo ocidental: nas trilhas do materialismo histórico. São Paulo: Boitempo, 2004.

BAIRNER, A. Sport, nationalism and globalization: european and north american perspectives. Albany: State University of New York, 2001.

"Re-appropriating Gramsci: Marxism, hegemony and sport". In: CARRING-

TON, B.; MCDONALD, I. (Org.). Marxism, cultural studies and sport. New York: Routledge, 2009. p. $195-212$.

BEAL, B. "Disqualifying the Official: An Exploration of Social Resistance Through the Subculture of Skateboarding". In: YIANNAKIS, A.; MELNICK, M. (Org.). Contemporary issues in sociology of sport. $4^{\text {th }}$. ed. rev. Champaign: Human Kinetics, 2001. p. 47-57.

BRACHT, V. Sociologia crítica do esporte: uma introdução. 3. ed. ljuí: Ed. da Unijuí, 2005.

CHAUÍ, M. Conformismo e resistência: aspectos da cultura popular no Brasil. 6. ed. São Paulo: Brasiliense, 1994.

COUTINHO, C. Gramsci: um estudo sobre seu pensamento político. 3. ed. rev. e amp. Rio de Janeiro: Civilização Brasileira, 2007.

DIAS, E. Gramsci em Turim: a construção do conceito de hegemonia. São Paulo: Xamã, 2000.

DONNELLY, P. "Sport as a Site for 'Popular' Resistance”. In: GRUNEAU, R. (Org.). Popular cultures and political practices. Toronto: Garamond, 1988. p. 69-82. 
GIULIANOTTI, R. Sport: a critical sociology. Cambridge: Polity, 2005.

GRAMSCI, A. Cadernos do cárcere. 4. ed. Rio de Janeiro: Civilização Brasileira, 2006a. v. I. Cadernos do cárcere. 4. ed. Rio de Janeiro: Civilização Brasileira, 2006b. v. 2. Cadernos do cárcere. 3. ed. Rio de Janeiro: Civilização Brasileira, 2007. v. 3. Cadernos do cárcere. Rio de Janeiro: Civilização Brasileira, 200 I . v. 4. Escritos políticos. Rio de Janeiro: Civilização Brasileira, 2004. v. I .

GRUPI, L. O conceito de hegemonia em Gramsci. 4. ed. Rio de Janeiro: Graal, 1978. HARGREAVES, J. (Ed.). Sport, culture and ideology. London: Routledge \& Kegan Paul, 1982. cap. 2. p. 30-6I.

HARGREAVES, J.; MCDONALD, I. Cultural studies and the sociology of sport. In: COAKLEY, J.; DUNNING, E. (Ed.). Handbook of sports studies. London: Sage, 2000. p. 48-60.

HOBSBAWM, E. História social do jazz. Rio de Janeiro: Paz e Terra, 1990.

MARX, K. O 18 brumário e cartas a Kugelmann. 2. ed. Rio de Janeiro: Paz e Terra, 1974. MÉSZÁROS, I. Filosofia, ideologia e ciência social. São Paulo: Boitempo, 2008.

MURAD, M. A violência e o futebol: dos estudos clássicos aos dias de hoje. Rio de Janeiro: Ed. da FGV, 2007.

RIGAUER, B. Marxist theories. In: COAKLEY, J.; DUNNING, E. (Ed.). Handbook of sports studies. London: Sage, 2000. p. 28-47.

ROWE, D. Antonio Gramsci: sport, hegemony and the national-popular. In: GIULIANOTTI, R. (Org.). Sport and modern social theorists. New York: Palgrave Macmillan, 2004. p. 97- I I 0. SIMSON, V.; JENNINGS, A. Os senhores dos anéis: poder, dinheiro e drogas nas olimpíadas modernas. São Paulo: Best Seller, 1992.

Recebido: 29 dez. 2010

Aprovado: 23 set. 2011

Endereço para correspondência:

Fabrício Luís Duarte Rua Hildebrando Oliva, I I58, apto. 340 Santa Mônica Uberlândia -MG CEP: $38408-212$ 